\title{
DIE REALITEIT VAN TRANSKULTURELE VERPLEGING: 'n ETIESE PERSPEKTIEF
}

\author{
Martha J Oosthuizen \\ MA Cur (Unisa) \\ Lektrise, Departement Gevorderde Verpleegwetenskappe, Universiteit van Suid-Afrika
}

Korrespondensie: oosthmj@unisa.ac.za

Sleutelwoorde: Transkulturele verpleging; kultuur; kultuursensitiewe sorg; verpleegkundige-pasiënt verhouding; kultuurverskillende pasiënte; houding

Keywords: Transcultural nursing; culture; culture-sensitive care; nurse-patient relationship; culturally different patients; attitude

\section{OPSOMMING}

Transkulturele verpleging verwys na die voorsiening van verpleegsorg aan pasiënte wie se kulturele waardes, oortuigings en lewenswyse van diè van die verpleegkundige verskil. Ten einde hulle etiese verpligting na te kom om sorg van hoogstaande gehalte aan alle pasiënte te lewer, moet verpleegkundiges oor die nodige kennis beskik om oor kultuurgrense te verpleeg.

Die doel met hierdie studie was om die mate waarin basiese, na-basiese en personeelontwikkelingsprogramme verpleegkundiges toerus om oor kultuurgrense te verpleeg en hul houdings jeens die kultureel-verskillende pasiënt te bepaal en om spesifieke probleme wat in die verpleging van die kultureel-verskillende pasiënt ervaar word, te identifiseer. Hierdie navorsing kan as kwantitatiewe navorsing geklassifiseer word. Data in hierdie beskrywende opnamenavorsing is deur middel van 'n vraelys ingesamel. Die navorsing is beperk tot geregistreerde verpleegkundiges in 'n akademiese hospitaal in Gauteng wat werksaam is in afdelings waar pasiënte oornag. Alle geregistreerde verpleegkundiges wat aan hierdie vereiste voldoen het, het deel uitgemaak van die populasie. Hierdie metode het verseker dat respondente van al die kultuurgroepe wat in die hospitaal verteenwoordig is ingesluit is. 'n Totaal van 219 geregistreerde verpleegkundiges het vraelyste ontvang. Geen bestaande vraelys was beskikbaar nie en die vraelys is deur die navorser ontwikkel. Die vraelys bestaan uit vyf afdelings wat biografiese besonderhede, vrae rakende respondente se basiese en na-registrasie opleiding, vrae oor professionele ondervinding, vrae oor respondente se houdings jeens kultureelverskillende pasiënte en probleme in transkulturele verpleging insluit. Die verwerking van die data is gedoen met behulp van 'n program wat volgens die SAS-stelsel (Statistical Analysis System) V.6.09 geskryf is. Daar is verder ook gebruik gemaak van die UNIX-stelsel vir die ontleding van enkele vrae. Data is verder verwerk met behulp van 'n variansie-analise (ANOVA SS).

Die bevindings van hierdie studie dui daarop dat verpleegkundiges wat kultureel-verskillende pasiënte verpleeg baie algemene ervarings en probleme deel. Alhoewel hulle dit as 'n uitdaging sien om pasiënte van verskillende kulture te verpleeg, is daar gevind dat hulle nie oor die nodige kennis beskik om kultuursensitiewe sorg te verskaf nie. Ander faktore soos die verpleegkundige se houding jeens kultureel-verskillende pasiënte, probleme met kommunikasie, wantroue en vooroordeel dra by tot die gebrek aan kultuursensitiewe sorg.

Die verpleegprofessie moet aan hierdie probleme aandag gee. Die verpleegprofessie sowel as die hospitaalowerhede het ' $n$ verantwoordelikheid teenoor die lede, werknemers en die pasiënte om verpleegkundiges toe te rus met die vaardighede en kennis wat hulle benodig om kultuursensitiewe sorg te verskaf. Probleme wat geïdentifiseer is moet aangespreek word en hospitale moet poog om unieke probleme te identifiseer en op te los.

\section{SUMMARY}

Transcultural nursing refers to the provision of nursing care to patients whose values, beliefs and life-style differ from those of the nurse. To enable nurses to honour their ethical obligation to provide quality care, they must have the necessary knowledge to nurse patients across cultural boundaries. 
The goal of this study was to determine the extent to which basic, post-basic and personnel development programs prepare nurses to nurse patients across cultural boundaries, to determine their attitudes towards the culturally different patient and to identify specific problems that nurses encounter when they nurse culturally different patients. This study could be classified as quantitative research. A questionnaire was used to collect data in this descriptive survey. The research is limited to registered nurses in an academic hospital in Gauteng in wards where patients stay overnight. The population consisted of all the registered nurses that met this requirement. This method ensured that respondents from all the different cultural groups represented in the hospital were included. A total of 219 registered nurses received questionnaires. The questionnaire was developed by the researcher and consists of five sections that include biographical data, questions regarding respondents' basic and and post-basic training, professional experience, attitudes towards culturally different patients and problems they encounter in transcultural nursing. The processing of the data was done on a program that was written according to the SAS-system (Statistical Analysis System) V.6.09. The UNIX-system was used for the analysis of some questions while further data analysis was done with a procedure known as analysis of variance (ANOVA SS).

The findings of the study suggest that nurses caring for culturally different patients share many common experiences and problems. Although they see it as a challenge to nurse patients from different cultures, it was found that they do not have the necessary knowledge to provide culture-sensitive care. Other factors, such as the nurse's attitude towards culturally different patients, problems with communication, mistrust and prejudice contribute to the lack of culturesensitive care.

It is recommended that the nursing profession pay attention to these problems. Both the nursing profession and the hospital authorities have a responsibility to the members, employees and the patients to provide nurses with the skills and knowledge they need to give culture-sensitive care. Problems that were identified should be addressed and hospitals must endeavour to identify and solve unique problems.

\section{INLEIDING EN PROBLEEMSTELLING}

Dit is ongetwyfeld so dat verpleegkundiges, van al die kategorieë gesondheidsorgpersoneel, die meeste kontak met die pasiënte in die saal het. Deur hierdie kontak word hulle blootgestel aan pasiënte vanuit verskeje kultuurgroepe. Die mens is ' $n$ kulturele en sosiale wese met talle behoeftes wat deur kulturele norme en interaksie met ander bevredig word. Dit is noodsaaklik om bewus te wees van verskille in kulturele waardes, norme en praktyke ten einde effektiewe en sensitiewe verpleegsorg te lewer (Leininger, 1970:83, 84; Henderson \& Primeaux, 1981:197; Lynam, 1992:149). Kultuur omvat gewoontes, oortuigings, kennis, taal, morele beginsels en sekere vaardighede in die kultuurgroep. Kultuur is ' $n$ integrale deel van die mens en kan nie van sorgsame verpleging geskei word nie.

Die bevindings van navorsing wat in Gauteng gedoen is om te bepaal in watter mate verpleegkundiges kultuursensitiewe sorg aan pasiënte verskaf asook probleme wat in transkulturele verpleging ondervind word, word in hierdie artikel bespreek.

Suid-Afrika is ' $n$ land van vele kulture. Alhoewel die meerderheid mense in Suid-Afrika swart is moet dit in gedagte gehou word dat hierdie meerderheid saamgestel is uit verskeie kultuurgroepe wie se taal, waardes, oortuigings en lewenswyse verskil. Volgens Masipa $(1991: 3,4)$ kompliseer dit die lewering van kultuursensitiewe sorg nog meer. Dit is sorg wat betekenisvol en sensitief is vir die behoeftes van pasiënte van alle kulture. Die mate waarin kultuursensitiewe sorg aan die pasiënt gelewer word, hang af van die houding van verpleegkundiges teenoor kultureel-verskillende pasiënte, asook die vlak van kennis waaroor hulle beskik om kultuursensitiewe sorg te beplan en te lewer. Indien die verpleegkundige nie sensitief is vir kultuurverskille by die pasiënte wat hy/sy verpleeg nie, is misverstande en probleme onafwendbaar. Dit hou ernstige etiese implikasies vir sorgsaamheid binne die verpleegkundigepasiënt-verhouding in. Volgens Henderson en Primeaux (1981:13) impliseer talle studies dat kulturele grense suksesvolle transkulturele verpleging hoogs onwaarskynlik maak.

Sorgsaamheid is die kern van verpleging en word gekenmerk deur empatie, ondersteuning, deernis, beskerming en inagneming van die individuele pasiënt se behoeftes, probleme en waardes (Leininger, 1984b:4). 
Volgens Henderson en Primeaux (1981:15) toon verpleegkundiges ' $n$ gebrek aan empatie, respek en sensitiwiteit teenoor pasiënte wat nie tot dieselfde etniese groep as hulle behoort nie. Die gevolg hiervan is wantroue, vooroordeel, vyandigheid, vrees, onverskilligheid, agterdog en rassisme (Perry, 1988:41; Eliason, 1993:226).

As professionele persoon het die verpleegkundige ' $\mathrm{n}$ etiese en morele verpligting om sorg van hoogstaande gehalte te lewer. Dit sal die kulturele waardes van die pasiënt in ag neem. Die pasiënt is geregtig daarop dat sy/haar kulturele waardes en lewenswyse in ag geneem word in verpleegpraktyke, en die verpleegkundige moet hierdie reg erken. Dit is noodsaaklik om te bepaal in watter mate die geregistreerde verpleegkundiges in ' $n$ transkulturele milieu hulle etiese verantwoordelikheid om sorgsaam te wees nakom en in watter mate verpleegsorg in die praktyk kultuursensitief is. Vrae wat ontstaan het is of die verpleegkundige in sy/haar basiese opleiding voldoende kennis verwerf om kultuursensitiewe sorg te verskaf, die pasiënt se reg tot kultuursensitiewe sorg erken word en in watter mate daaraan uitvoering gegee word?

\section{DEFINIERING VAN KONSEPTE}

Kultuur: word gedefinieer as die waardes, norme, oortuigings en praktyke van 'n spesifieke groep. Dit is aangeleer en word gedeel deur die groep. Dit rig denke, besluite en optrede op ' $n$ bepaalde manier (Giger \& Davidhizar, 1991:4).

Transkulturele verpleging: is gemoeid met die voorsiening van verpleegsorg aan pasiënte wie se kulturele waardes, oortuigings en lewenswyse verskil van die van die verpleegkundige (Boyle \& Andrews, 1989:3, 4).

Kultuursensitiewe sorg: Onder kultuursensitiewe sorg word verstaan verpleegsorg wat betekenisvol en sensitief is vir die behoeftes van pasiënte van alle kulture.

\section{DOEL MET DIE STUDIE}

\section{Die doel met hierdie navorsing was om}

- die mate waarin basiese, na-basiese en personeel-ontwikkelingsprogrammeverpleeg- kundiges toerus om oor kultuurgrense te verpleeg, te bepaal;

- die mate waarin die verpleegkundige die pasiënt se reg tot kultuursensitiewe sorg erken, te bepaal;

- die mate waarin kultuursensitiewe sorg wel aan die pasiënt gelewer word, te bepaal;

- die houding van die professionele verpleegkundige jeens kultureel-verskillende pasiënte, te bepaal; en

- die aard van probleme wat in transkulturele verpleging ońdervind word, te identifiseer.

\section{LITERATUURSTUDIE}

Die realiteit van transkulturele verpleging is dikwels minder rooskleurig as die ideaal. In die bestudering van literatuur is gekyk na faktore wat moontlik ' $n$ invloed op sorgsaamheid in die verpleging van kultureelverskillende pasiënte kan uitoefen. Talle faktore kan daartoe bydra dat transkulturele verpleging nie suksesvol is nie. Hieronder tel die geregistreerde verpleegkundige se kennis oor kultureel-verskillende pasiënte, asook sy/ haar houding jeens pasiënte wie se kulturele afkoms van hom/haar verskil. Die literatuurstudie het spesifieke probleme wat in die verpleging van kultureel-verskillende pasiënte ervaar word aan die lig gebring en dit kon in die vraelys geïnkorporeer word.

Vanuit die literatuur wat bestudeer is wil dit voorkom asof sensitiwiteit vir kulturele verskille slegs een van verskeie aspekte is wat tot suksesvolle verpleging oor kultuurgrense kan bydra. In ' $n$ verslag aan die American Academy of Nursing beveel die Expert Panel on Culturally Competent Nursing Care aan dat verpleegkundiges se opleiding hulle moet voorberei om in ' $n$ multikulturele verpleegwêreld te funksioneer (Davis, Dumas, Ferketich, Flaherty, Isenberg, Koerner, Lacey, Stern, Valente en Maleis, 1992:277-283). Volgens Davis et al. (1992:278) sal die verpleegkundige wat bevoeg is om kultuursensitiewe sorg te verskaf, gebruik maak van 'n transkulturele verpleegteorie, modelle en navorsingsbeginsels ten einde gesondheidsorgbehoeftes te identifiseer en sorg te verskaf. Hierdie sorg word binne die kulturele konteks van die pasiënt verskaf.

Verskeie navorsers en outeurs onderskryf die belang van 
kennis oor kulturele verskille by pasiënte. 'n Amerikaanse verpleegkundige/antropoloog, Madeleine Leininger, het die grondslag gelê vir transkulturele verpleegopleiding. Volgens Leininger (1984a:42) het die verpleegkundige ' $n$ kennisbasis van transkulturele verpleging nodig om te verseker dat alle pasiënte effektiewe en professionele pasiëntesorg ontvang. Tripp-Reimer, Brink en Saunders (1984:78) is ook van mening dat verpleegkundiges voorberei moet word om pasiënte van verskillende kulture te verpleeg en om verpleegsorg te verskaf op 'n wyse wat toepaslik is vir elke pasiënt. Wanneer die verpleegkundige begrip het vir die spesifieke faktore wat mense se gesondheid beïnvloed is hy/sy beter in staat om die pasiënt se behoeftes te bevredig. Die standpunt van die Suid-Afrikaanse Raad op Verpleging is dat die verpleegkurrikulum voorsiening moet maak vir persoonlike en professionele ontwikkeling van die student sodat "hy by voltooing van die studiekursus respek toon vir die waardigheid en uniekheid van die mens in sy sosiaal-kulturele en religieuse verband en hom as 'n psigiese, fisiese en sosiale wese binne hierdie verband benader en verstaan" (Suid-Afrikaanse Raad op Verpleging, 1985:2).

Dit is belangrik dat die verpleegkundige die verhouding tussen kultuur en gesondheid/siektegedrag verstaan. Kultuur kan nie van die verpleegkundige se interaksie met die pasiënt geskei word nie. Daar moet dus duidelik aandag geskenk word aan kulturele perspektiewe in die verpleegkurrikulum (Capers, 1992:20).

Uit die literatuur wat bestudeer is, is dit duidelik dat die verpleegkundige toegerus moet word met kennis van transkulturele verpleging ten einde effektiewe en bekwame sorg aan alle pasiënte te verskaf. Die verpleegkundige wat dikwels kultureel-verskillende pasiënte moet versorg sonder dat hy/sy oor die nodige kennis beskik, kan frustrasie ervaar wat 'n negatiewe invloed op sowel die verpleegkundige as die pasiënt kan hê. Hierdie pasiënte word soms deur die verpleegkundige geëtiketteer as "moeilike" pasiënte en is dan ongewild. Voortdurende blootstelling kan tot werksontevredenheid en uiteindelike diensverlating lei. 'n Gefrustreerde verpleegkundige sal dit moeilik vind om ' $n$ warm en sensitiewe verhouding met die pasiënt te bou en kan die pasiënt skade berokken (Kus in McCloskey \& Grace, 1990:555).
Het pasiënte die reg tot kultuursensitiewe verpleegsorg? Volgens Leininger (1991:21) het mense van enige kultuurgroep in die wêreld die reg om te eis dat hulle kulturele sorgwaardes geken, gerespekteer en toepaslik gebruik word in verpleging en ander gesondheidsorgdienste. Eliason (1993:225) het bevind dat daar groeiende erkenning onder verpleegkundiges is dat "...to treat all clients equally means to treat some of them poorly". Verpleegsorg op grond van individuele behoeftes kan egter net verskaf word as die verpleegkundige in staat is om kultureel-verskillende behoeftes te herken en effektief daaraan aandag te gee.

Verpleegkundiges kom voortdurend in aanraking met pasiënte wat tot ander kultuurgroepe as die van die verpleegkundige behoort. Kultuurverskille hou egter 'n bedreiging in vir ' $n$ sorgsame verpleegkundige-pasiëntverhouding. Een van die faktore wat ' $n$ invloed op die verhouding kan uitoefen is die verpleegkundige se houding jeens kultureel-verskillende pasiënte. In 'n studie deur Rooda (1993:209-213) is bevind dat individue heel waarskynlik meer positief sal wees teenoor hul eie etniese en kultuurgroep as teenoor ander. Rooda het haar navorsing in 'n mid-westerse distrik in die VSA gedoen. In Brittanje word soortgelyke probleme as in die VSA ondervind. Verskeie navorsers het reeds bevind dat die individuele behoeftes van etniese minderhede nie voldoende aandag kry in die hospitaal nie. Volgens Murphy en Macleod Clark (1993:442) is getuienis gevind van afbrekende houdings teenoor en stereotipering van Asiatiese pasiënte deur gesondheidsorgwerkers. Gevalle van onsensitiewe behandeling en onkunde is by baie personeel gerapporteer.

In die studie deur Murphy en Macleod Clark (1993:449) is bevind dat baie verpleegkundiges gevoelens van stress en frustrasie ervaar wanneer holistiese verpleegsorg weens kultuurverskille nie moontlik is nie. ' $n$ Verdere bevinding was dat die meerderheid verpleegkundiges probleme ondervind het om 'n goeie verhouding met die pasiënt te bou. Kommunikasieprobleme en vooroordele het hiertoe bygedra.

Die behoefte om transkulturele konsepte in verpleegonderwys te inkorporeer, blyk duidelik uit die literatuur wat bestudeer is. Probleme in transkulturele verpleging kom wêreldwyd voor, maar is dikwels die gevolg van onkunde of negatiewe gevoelens by die 
verpleegkundige. Indien die verpleegkundige ' $\mathrm{n}$ kulturele bewuswording ontwikkel, kan hierdie probleme geïdentifiseer en positiewe oplossings gevind word.

\section{NAVORSINGSONTWERP EN -METODE}

Hierdie navorsing kan as kwantitatiewe navorsing geklassifiseer word. Navorsing waarin die kwantitatiewe benadering gevolg word toon die volgende algemene kenmerke, naamlik dit fokus op ' $n$ klein aantal spesifieke konsepte, begin met voorafopgestelde idees oor hoe die konsepte onderling verwant is, gebruik formele instrumente en gestruktureerde prosedures om inligting te bekom, versamel inligting onder gekontroleerde toestande, beklemtoon objektiwiteit in die insameling en ontleding van inligting en ontleed numeriese inligting deur statistiese prosedures (Polit \& Hungler, 1991:24). 'n Beskrywende opname is met behulp van ' $n$ vraelys gedoen om te bepaal in watter mate die verpleegkundige toegerus is om kultureel-verskillende pasiënte te verpleeg, wat die verpleegkundige se houding jeens die kultureel-verskillende pasiënt is en in watter mate probleme in transkulturele verpleging ervaar word.

\section{Populasie en steekproef}

Die doel met hierdie navorsing was om te bepaal in watter mate kultuursensitiewe verpleegsorg verskaf word. 'n Groot akademiese hospitaal in Gauteng waar verpleegsorg oor kultuurgrense algemeen voorkom is geïdentifiseer. Die navorsing is beperk tot geregistreerde verpleegkundiges wat werksaam is in afdelings waar pasiënte oornag. Verpleegkundiges werksaam in klinieke of ander afdelings waar pasiënte nie oornag nie was van hierdie navorsing uitgesluit.

Die navorser het met behulp van die wissellys al die verpleegkundiges geïdentifiseer wat aan die teikenpopulasie voldoen het. Hierdie lys bevat name van alle verpleegkundiges werksaam in die betrokke hospitaal. Slegs verpleegkundiges werksaam in sale waar pasiënte oornag is vir die doel van die navorsing geïdentifiseer. Die name van alle geregistreerde verpleegkundiges wat aan hierdie vereiste voldoen is op ' $n$ lys geplaas. Al die verpleegkundiges wie se name op die lys verskyn, is by die navorsing betrek. Aangesien hierdie navorsing kultuurverskille bestudeer, is die navorser van mening dat hierdie metode verseker het dat respondente van al die kultuurgroepe in die navorsing verteenwoordig is. ' $n$ Totaal van 249 verpleegkundiges vanuit verskeie kultuurgroepe is geïdentifiseer om aan die navorsing deel te neem. Die verspreiding van vraelyste is beperk tot twee weke en slegs verpleegkundiges wat gedurende daardie twee weke aan diens was het vraelyste ontvang.

\section{Die navorsingsinstrument}

Vanweë die sensitiewe aard van die navorsing is daar op 'n vraelys besluit. Geen bestaande vraelys was beskikbaar nie en die vraelys is deur die navorser ontwikkel. Die vraelys is ontwikkel aan die hand van die literatuur wat geraadpleeg is, gesprekke met $n$ kundige by die Departement Antropologie by Unisa en die hulp van ' $n$ statistikus.

\section{Uiteensetting van die vraelys}

Daar is in hierdie navorsing van twee vlakke van meting gebruik gemaak, naamlik nominale en ordinale skale. Waar bepaalde eienskappe van respondente verlang is om hulle in bepaalde kultuurgroepe te plaas is nominale meting gebruik. Daar is verder van ordinale meting gebruik gemaak waar bepaalde eienskappe op verskillende vlakke gemeet is. Die algemeenste metode om houdings te meet is, volgens Polit en Hungler (1991:302), met behulp van die Likert-skaal. Daar is in hierdie vraelys gebruik gemaak van die Likert-skaal waar verpleegkundiges se houdings teenoor kultureelverskillende pasiënte gemeet is. Waar van respondente verwag is om aan te dui hoe dikwels sekere praktyke gevolg word of hoe dikwels probleme ervaar word, is van die grafiese takseringskaal gebruik gemaak. Die vraelys bestaan uit vyf afdelings. Afdeling 1 bevat inligting rakende die respondent se biografiese besonderhede. Vrae oor die respondent se kultuurafkoms is in hierdie afdeling ingesluit. Afdeling 2 handel oor vrae rakende die respondent se basiese- sowel as na-registrasie verpleegopleiding. Responidente moes aandui in watter mate hulle basiese opleiding hulle voorberei het om kultureel-verskillende pasiënte te verpleeg en tot watter mate aspekte van transkulturele verpleging in naregistrasie kursusse aangespreek word. Hier is gebruik gemaak van sowel oop as geslote vrae. In afdeling 3 is van die respondent verwag om vrae oor professionele ondervinding te beantwoord. Vrae oor die hospitaal se personeelontwikkelingsprogramme is in hierdie afdeling 
ingesluit. Afdeling 4 bevat stellings oor die respondent se houding jeens en ervaring van kultureel-verskillende pasiënte. Dit sluit ook vrae in wat betrekking het op die lewering van kultuursensitiewe verpleegsorg. Waar respondente se houdings getoets is, is gebruik gemaak van ' $\mathrm{n}$ Likert-skaal en moes respondente in vyf kategorieë aandui in watter mate hulle met ' $n$ stelling saamstem aldan nie. By stellings wat betrekking het op die lewering van kultuursensitiewe sorg is van 'n grafiese takseringskaal gebruik gemaak. Afdeling 5 bevat ' $n$ lys van faktore wat moontlik kan lei tot probleme of konflik in transkulturele verpleging. Met behulp van ' $n$ grafiese takseringskaal moes respondente aandui in watter mate hulle probleme ondervind aldan nie. Ruimte is gelaat vir respondente om kommentaar te lewer of probleme te bespreek.

\section{Voortoets}

As voortoets is die vraelys aan verpleegkundiges gegee wat pasiënte vanuit verskillende kultuurgroepe verpleeg het maar wat nie aan die hospitaal verbonde was waar hierdie navorsing gedoen is nie. Enkele wysigings is hierna aan die vraelys aangebring.

\section{Die geldigheid en betroubaarheid van die vraelyste}

Ten einde die geldigheid van die navorsingsinstrument te verseker is die vraelys aan kundiges wat oor ' $n$ verpleegonderwyskwalifikasie beskik gegee om te bepaal of die vrae sinvol is.

Die inhoud van die vraelys is bepaal op grond van die literatuur wat bestudeer is. Die vraelys is voorts deur kundiges wat ' $n$ belangstelling in die studieveld het geëvalueer vir inhoudsgeldigheid.

Die betroubaarheid van die instrument is bepaal deurdat vrae in die voortoets dieselfde geinterpreteer is as deur respondente wat aan die navorsing deelgeneem het. Die vraelyste is oor 'n tydperk van twee weke aan respondente uitgedeel en weereens was daar nie 'n verskil in interpretasie van vrae deur respondente nie.

\section{Etiese aspekte en toestemming vir die navorsing}

Toestemming om die navorsing te doen is van die Direkteur-generaal, Gesondheid, van die Gauteng Provinsiale Regering en die Superintendent van die hospitaal verkry. Respondente is ingelig oor die doel van die navorsing, asook hul reg op vrywillige deelname. Respondente is verseker van vertroulikheid en anonimiteit.

\section{Insameling en verwerking van data}

Die vraelyste is tesame met ' $n$ dekkende brief persoonlik tydens verskillende skofte aan respondente uitgedeel. Respondente is deurgaans verseker van anonimiteit en dit is benadruk dat hulle nie hulle name op die vraelyste moes aanbring nie. ' $n$ Totaal van 214 vraelyste is gedurende die twee weke wat vooraf bepaal is deur die navorser persoonlik aan die respondente uitgedeel. Respondente wat met behulp van die wissellys geïdentifiseer is maar nie aan diens was gedurende hierdie twee weke nie het nie vraelyste ontvang nie. 'n Totaal van 150 bruikbare vraelyste $(70,1 \%)$ is terugontvang.

Die data is verwerk met behulp van ' $n$ program wat volgens die SAS-stelsel (Statistical Analysis System) V.6.09 geskryf is. Daar is verder ook gebruik gemaak van die UNIX-stelsel vir ontleding van enkele vrae. Data in een afdeling van die vraelys is verder verwerk met behulp van ' $n$ variansie-analise (ANOVA SS).

\section{ONTLEDING EN INTERPRETASIE VAN DATA}

'n Totaal van 214 vraelyste is versprei, waarvan 160 $(74,8 \%)$ terugontvang is. Van die 160 vraelyste was tien $(6,3 \%)$ onbruikbaar omdat dit of nie ingevul is nie of slegs gedeeltelik ingevul is. Die totale aantal vraelyste wat ontleed is, is $150(70,1 \%)$.

Aangesien hierdie navorsing oor kultuurverskille tussen die verpleegkundige en die pasiënt gehandel het, was dit belangrik om te bepaal tot watter kultuurgroep die respondent behoort. Daar is vir diè doel twee kriteria gekies naamlik die respondent se bevolkingsgroep en huistaal. In Tabel 1 kan gesien word dat 58 respondente $(38,7 \%)$ blank en 26 respondente $(17,3 \%)$ Kleurlinge was. Ses-en-sestig $(44,0 \%)$ respondente het tot een van die swart bevolkingsgroepe behoort met Tswana 26 
$(17,3 \%)$ en Noord-Sotho $16(10,8 \%)$ wat in die hoogste persentasie teenwoordig was. Die Twanas en NoordSothos se natuurlike woongebiede is in die geografiese gebied waarin die hospitaal geleë is waar hierdie navorsing gedoen is, wat moontlik verklaar waarom die respondente uit hierdie twee kultuurgroepe in die meerderheid was.

Tabel 1: Bevolkingsgroep van respondente

\begin{tabular}{|l|c|c|}
\hline BEVOLKINGSGROEP & FREKWENSIE & PERSENTASIE \\
\hline Blank & 58 & 38,7 \\
Kleurling & 26 & 17,3 \\
Ndebele & 6 & 4,0 \\
Noord-Sotho & 16 & 10,8 \\
Suid-Sotho & 3 & 2,0 \\
Swazi & 2 & 1,3 \\
Tsonga & 8 & 5,3 \\
Tswara & 26 & 17,3 \\
Xhosa & 2 & 1,3 \\
Zoeloe & 3 & 2,0 \\
\hline TOTAAL & $N=150$ & 100,0 \\
\hline
\end{tabular}

Die taal wat ' $n$ mens praat, vorm deel van die kultuurgroep waartoe hy/sy behoort. Tabel 2 dui die respondente se huistaal aan.

Tabel 2: Huistaal van respondente

\begin{tabular}{|l|c|c|}
\hline HuISTAAL & FREKWENSIE & PERSENTASIE \\
\hline Airkaans & 73 & 48,6 \\
Engels & 13 & 8.7 \\
Ndtebele & 1 & 0,7 \\
Noord-Sotho & 23 & 15,3 \\
Suid-Sotho & 2 & 1,3 \\
Tsonga & 3 & 2,0 \\
Tswana & 30 & 20,0 \\
Xhosa & 1 & 0,7 \\
Zoeloe & 3 & 2,0 \\
Ander & 1 & 0,7 \\
\hline & & \\
\hline TOTAAL & $\mathrm{N}=\mathbf{t} 50$ & 100,0 \\
\hline
\end{tabular}

Dit blyk uit Tabel 2 dat 73 van die respondente $(48,6 \%)$ Afrikaanssprekend was, 13 van die respondente $(8,7 \%)$
Engelssprekend was en 63 van die respondente (42,0\%) een van die amptelike swart tale as huistaal het. Kommunikasie is een van die grootste struikelblokke in transkulturele verpleging. Daarom was dit vir die navorser belangrik om te bepaal watter tale respondente kan praat buiten hulle huistaal. Daar is bevind dat al die respondente, naamlik $150(100,0 \%)$ Engels kan praat, maar dat ses van die respondente $(4,0 \%)$ nie Afrikaans kan praat nie. Met behulp van statistiese ontleding is bepaal dat slegs 28 blanke en Kleurling respondente $(18,7 \%)$ aangedui het dat hulle een van die swart tale kan praat. Hieruit was dit duidelik dat kommunikasieprobleme kon voorkom.

Die inligting wat van die respondente verkry is, dui daarop dat die verpleegkundiges in hierdie hospitaal op groot skaal pasiënte uit 'n groot aantal kultuurgroepe moet verpleeg.

\section{BEVINDINGS EN GEVOLGTREKKINGS AAN DIE HAND VAN DIE DOELWITTE VAN HIERDIE STUDIE}

Die mate waarin basiese, na-basiese en personeel-ontwikkelingsprogramme verpleegkundiges toerus om oor kultuurgrense te verpleeg

Alhoewel 74 respondente $(49,4 \%)$ aangedui het dat hulle tydens hulle basiese opleiding lesings gehad het oor transkulturele verpleging was slegs 30 respondente $(20,0 \%)$ van mening dat hulle basiese opleiding hulle voldoende voorberei het om kultureel-verskillende pasiënte te verpleeg. Verskeie respondente het bygevoeg dat "lesings baie oorsigtelik was", "slegs 'n halfuur in beslag geneem het" of "slegs gehandel het oor godsdienstige verskille by enkele kultuurgroepe". Personeelontwikkelingsprogramme voorsien ook nie in die behoeftes van verpleegkundiges om meer kennis te verwerf aangaande die kultuurgroepe wat hulle verpleeg nie. Daar is bevind dat 58 van die respondente $(38,6 \%)$ nooit lesings oor transkulturele verpleging tydens personeelontwikkelingsprogramme ontvang het nie en 'n verdere 33 respondente $(22,0 \%)$ nie weet of sulke lesings aangebied word nie. Respondente in hierdie navorsing het in ' $n$ groot mate aangedui dat hulle van mening is dat hulle nie voldoende vir die verpleging van kultureel-verskillende pasiënte voorberei is nie. Die 
bevindings oor geregistreerde verpleegkundiges se kennis van transkulturele verpleging is kommerwekkend. Daar is tot die gevolgtrekking gekom dat die verpleegkundige nie van mening is dat die basiese, nabasiese en personeelontwikkelingsprogramme hulle met die nodige kennis toerus om kultureel-verskillende pasiënte te verpleeg nie.

\section{Die mate waarin die verpleegkundige die pasiënt se reg tot kultuursensitiewe sorg erken}

Die respondente wat aan hierdie navorsing deelgeneem het, het met ' $n$ oorweldigende meerderheid, naamlik $90,6 \%$ aangedui dat die verpleegkundige 'n verantwoordelikheid het om van ander kulture te leer. Tog was 60 van die respondente (40\%) van mening dat omvattende verpleegsorg moontlik is al word kulturele faktore nie in ag geneem nie terwyl ' $n$ verdere 28 respondente $(18,7 \%)$ onseker was of omvattende sorg wel moontlik is. Bykans eweveel respondente was van mening dat te veel klem vandag in verpleegliteratuur op kultuursensitewe sorg geplaas word as wat nie die mening gehuldig het nie. Die aantal respondente naamlik $44(29,5 \%)$ wat onseker was, was opvallend hoog, wat 'n aanduiding kan wees dat hierdie respondente nie op hoogte is van die jongste verpleegliteratuur nie.

\section{Die mate waarin kultuursensitiewe sorg aan die pasiënt gelewer word}

Alhoewel die meerderheid respondente aangedui het dat kultuurverskille in ag geneem word wanneer kultureelverskillende pasiënte verpleeg word was 70,7 persent van die respondente van mening dat verpleegkundiges nie op hoogte is van die kultuurafkoms van die pasiënte wat hulle verpleeg nie. Dit wil dus voorkom asof spesifieke kultuurverskille in ag geneem word wanneer verpleegkundiges daarvan bewus is, maar dat hulle dikwels nie kennis dra van die pasiënt se kultuurafkoms nie en dus nie bewus sal wees van spesifieke kulturele gebruike of tradisies wat vir die pasiënt belangrik is nie.

\section{Die houding van die professionele verpleegkundige jeens kultureel- verskillende pasiënte}

In navorsing wat deur Bonaparte (1979:167) gedoen is, is bevind dat "...clients from different cultural or ethnic groups who are perceived as having health-care values, beliefs and practices which differ from those of the healthcare providers are more likely to elicit negative attitudes than clients whose health-illness beliefs and values are similar".

Die meerderheid respondente wat aan hierdie navorsing deelgeneem het, naamlik $66(44,3 \%)$ het saamgestem met die stelling dat hul houding jeens kultureelverskillende pasiënte verskil van hul houding jeens pasiënte van hul eie kultuurgroep, terwyl $58(38,9 \%)$ nie saamgestem het met die stelling dat hul houding verskil nie. Vyf-en-twintig van die respondente $(16,8 \%)$ was onseker of hulle houdings verskil. Alhoewel die meerderheid respondente nie die verpleging van kultureel-verskillende pasiënte as negatief ervaar nie vind hulle dit moeilik om ' $n$ sorgsame verpleegkundigepasiënt-verhouding met die kultureel-verskillende pasiënt te bou. Slegs vier-en-sestig respondente $(43,2 \%)$ was van mening dat vooroordele nie verhoudings met kultureel-verskillende pasiënte beïnvloed nie.

\section{Die aard van probleme wat in transkulturele verpleging ondervind word}

Navorsing in die Verenigde State van Amerika en Brittanje het verskeie probleme in transkulturele verpleging aan die lig gebring. Alhoewel elke land se kultuursamestelling eiesoortig is kan daar aanvaar word dat sommige van die probleme wat reeds in ander lande geïdentifiseer is, ook hier sal voorkom. Areas waarin respondente wat aan hierdie navorsing deelgeneem het probleme ervaar, is die volgende:

\section{Kommunikasie}

Goeie kommunikasie tussen die verpleegkundige en die pasiënt is noodsaaklik indien totale pasiëntesorg in 'n sorgsame verpleegkundige-pasiënt-verhouding bereik wil word. Slegs 32 respondente $(22,0 \%)$ ervaar selde of nooit probleme met kommunikasie nie. Die kommunikasieprobleem is die grootste probleem wat in transkulturele verpleging ervaar word. Dit gebeur dat verpleegkundiges en kultureel-verskillende pasiënte mekaar weens taalverskille nie verstaan nie. Een respondent se kommentaar dui op die implikasies van die probleem "... very difficult for black patients who don't know either Afrikaans or English to verbalise their 
grievances - e.g. pain, they will never complain of pain unless otherwise asked, if there are only white nurses on duty". Die meerderheid respondente, naamlik 98 $(65,3 \%)$, het aangedui dat nie-verpleegkundige personeel gebruik word om prosedures aan pasiënte te verduidelik indien probleme met die taal ondervind word. Aangesien daar nie 'n tolk op die personeel van die hospitaal was nie is gebruik gemaak van enigiemand wat die pasiënt se taal kan praat. Dit sluit skoonmakers, bodes, portiere en familielede van pasiënte in.

\section{Verpleegkundige-pasiënt-verhouding}

'n Sorgsame verpleegkundige-pasiënt-verhouding vorm die grondslag van verpleging. Een-en-negentig van die respondente $(63,2 \%)$ het probleme ervaar om 'n sorgsame verhouding met die kultureel-verskillende pasiënt te bou. In 'n studie in die Verenigde Koninkryk het Murphy en Macleod Clark (1993:445) bevind dat 55 persent van die verpleegkundiges wat aan hulle navorsing deelgeneem het probleme ervaar het om ' $n$ goeie verhouding met die pasiënt te bou.

\section{Gewoontes en gebruike}

Alhoewel dit nie deur 'n groot aantal respondente as 'n probleem ervaar word nie het sommige respondente pasiënte se eetgewoontes en godsdienstige gebruike as problematies evvaar. Respondente het egter verskeie probleme met pasiënte se besoekers. Dit gee aanleiding tot onsekerheid by die pasiënte en kan lei tot konflik en wrywing tussen die verpleegkundige en die pasiënt.

\section{Vooroordeel}

Vooroordeel by een kultuurgroep teenoor 'n ander kultuurgroep kom dikwels voor. Ongeveer die helfte van die respondente, 49,3 persent, het aangedui dat hulle vooroordeel by die pasiënt ervaar. Die volgende kommentaar van respondente dui op wantroue teenoor verpleegpersoneel wat van kultuurafkoms met die pasiënt verskil:

- $\quad$ "... Some culturally different patients believe that just because you are different, you are either unable or less capable of taking care of them". "There are some people who do not at all accomodate or tolerate some cultures. Xhosas are negative to other cultures, are ethnocentric. Indians have no trust in us as blacks or hospital staff. Their children are given some traditional medicine in the ward. They prefer washing them personally".

- $\quad$ "I have experienced problems with black children who are terrified of white nurses".

\section{GEVOLGTREKKINGS EN IMPLIKASIES VIR DIE VERPLEEGPRAKTYK}

As professionele persoon het die verpleegkundige 'n morele en etiese verpligting om sorg van hoogstaande gehalte te lewer. Volgens Leininger (1984a:43) kan hierdie morele verpligting egter nie nagekom word as die verpleegkundige nie bewus is van die pasiënt se waardes, gevoelens en oortuigings nie. Die pasiënt het die reg om te verwag dat sy kulturele waardes en lewenswyse in ag geneem word in verpleegpraktyke en die verpleegkundige moet hierdie reg erken.

Die bevindings in hierdie navorsing dui daarop dat verpleegkundiges in 'n transkulturele verpleegomgewing nie hul etiese verpligtings nakom nie. Die grootste struikelblok is probleme met kommunikasie. Dit gee aanleiding tot verskeie etiese kwessies. Die bevinding dat die hulp van skoonmakers, portiere en dikwels enige persoon wat op die betrokke oomblik in die saal is ingeroep word om aan 'n pasiënt prosedures te verduidelik dui op 'n skending van die pasiënt se reg op vertroulikheid en privaatheid. Daar rus 'n etiese verpligting op die verpleegkundige om vertroulikheid te handhaaf. Volgens Strauss (1993:17) kan dit as 'n ernstige etiese vergryp beskou word indien hierdie verpligting nie nagekom word nie. Die omvang van probleme met kommunikasie wek kommer. Die pasiënt het die reg om op grond van voldoende inligting toestemming te gee of te weier dat prosedures uitgevoer of chirurgiese ingrepe gedoen word. Dit is egter te betwyfel of die pasiënt ten volle ingelig is oor die prosedure indien kommunikasie met pasiënte deur middel van portiere en skoonmakers geskied. Volgens Kirstein in Pera en Van Tonder (1996:164) word die pasiënt se reg om te besluit wat met sy eie liggaam gedoen mag word as ' $n$ basiese mensereg beskou. Oningeligte toestemming moet dus as 'n skending van hierdie reg gesien word.

Die probleme wat deur verpleegkundiges met kultureelverskillende pasiënte se besoekers ervaar word is uiteenlopend. Wantroue, vooroordeel en 'n gebrek aan insig in besoektye by besoekers dra by tot die probleme. 
Sorgsame verpleegsorg vereis dat verpleegkundiges groter begrip vir die gebruike van ander kulture sal hê. Meer buigbare besoektye of die daarstelling van sitkamers waar pasiënte hulle besoekers kan ontvang kan moontlik sommige van die probleme wat besoekers veroorsaak verminder.

In die verpleegkundige-pasiënt-verhouding is etiese verpligtings ter sprake. Etiese sorg vereis van die verpleegkundige om binne die verpleegkundige-pasiëntverhouding sorgsaam op te tree. Dit vereis dat verpleegkundiges die waardes en oortuigings van hulle pasiënte moet respekteer. Dit vereis verder dat hulle mekaar moet vertrou en dat die verpleegkundige aanspreeklikheid moet aanvaar vir haar optrede. Indien die meerderheid respondente probleme ervaar om 'n sorgsame verhouding met die kultureel-verskillende pasiënt te bou, word hierdie etiese verpligtings nie nagekom nie.

Wantroue en vooroordeel maak dit onmoontlik vir die verpleegkundige om 'n sorgsame verhouding met die pasiënt te bou. Vooroordele kan egter te bowe gekom word indien die verpleegkundige respek toon vir die pasiënt ongeag sy/haar kultuurafkoms.

\section{BEPERKINGS}

Alhoewel respondente tot tien bevolkingsgroepe behoort, is slegs die personeel van een groot akademiese hospitaal in Gauteng by hierdie navorsing betrek, wat veralgemenings beperk. Baie min Suid-Afrikaanse literatuur was beskikbaar. Die navorser se literatuurstudie bestaan grootliks uit buitelandse literatuur. Dit is moontlik dat enkele respondente antwoorde verskaf het wat polities korrek is maar nie hulle ware gevoelens weerspieël nie.

\section{AANBEVELINGS}

Die verpleegprofessie sowel as die hospitaalowerheid het ' $n$ verantwoordelikheid teenoor sy lede en werknemers, asook teenoor die pasiënte, om verpleegkundiges toe te rus met vaardighede wat hulle nodig het om kultuursensitiewe sorg te verskaf. Ten einde hierdie verantwoordelikheid na te kom, moet lesings oor transkulturele verpleging in die kurrikulum van basiese verpleegkursusse voorgeskryf word. Transkulturele verpleeginhoud behoort ook in na-registrasie-kursusse aangebied te word. Personeelontwikkelingsprogramme behoort werknemers toe te rus met kennis rakende die spesifieke kultuurgroepe wat meestal in ' $n$ hospitaal verpleeg word. Probleme wat geïdentifiseer is, moet aangespreek word en hospitale moet poog om unieke probleme te identifiseer en op te los.

\section{SLOTOPMERKING}

Die gebrek aan kennis oor transkulturele verpleging, kommunikasieprobleme, wantroue en vooroordeel wat tussen die verpleegkundige en die kultureel-verskillende pasiënt voorkom, maak sorgsame kultuursensitiewe verpleegsorg bykans onmoontlik. In hierdie studie is daar nie genoegsame bewyse gevind dat verpleging oor kultuurgrense kultuursensitief is nie. Dit is noodsaaklik dat die probleme en knelpunte in transkulturele verpleging deur die verpleegprofessie aangespreek word.

\section{BRONNELYS}

Bonaparte, BH 1979: Ego defensiveness, open-closed mindedness, and nurses' attitude toward culturally different patients. Nursing Research, 28(3):166-171.

Boyle, JS \& Andrews, MM 1989: Transcultural concepts in nursing care. Glenview, Illinois: Scott Foresman.

Capers, CF 1992: Teaching cultural content: a nursing education imperative. Holistic Nursing Practice, 6(3):19-28.

Davis, LH; Dumas, R; Ferketich, S; Flaherty, MJ; Isenberg, M; Koerner, JE; Lacey, B; Stern, PN; Valente, S \& Maleis, Al 1992: AAN Expert Panel Report. Culturally competent health care. Nursing Outlook, 40(6):277-283.

Eliason, MJ 1993: Ethics and transcultural nursing care. Nursing Outlook, 41(5):225-228.

Giger, JN \& Davidhizar, RE 1991: Transcultural nursing: assessment and intervention. St Louis: Mosby.

Henderson, G \& Primeaux, M 1981: Transcultural health care. Menlo Park, California:Addison-Wesiey.

Kirstein, H 1996: Ingeligte toestemming, vertroulikheid en die waarheid vertel (In: SA Pera \& S van Tonder red. 1996: Etiek in die verpleegpraktyk. Kaapstad: Juta \& Kie, Bpk, pp. 161-173.)

Kus, RJ 1990: Nurses and unpopular clients, (In: JC McCloskey \& HK Grace eds. 1990: Current issues in nursing. St. Louis: The CV Mosby Company, pp. 554-558).

Leininger, MM 1970: Nursing and anthropology: two worlds to blend. New York: John Wiley \& Sons, Inc. 
Leininger, MM 1984a: Transcultural nursing: an essential knowledge and practice field for today. Canadian Nurse, 80(11):41-45.

Leininger, MM 1984b: Care. The essence of nursing and health. Thorofare, NJ: Slack incorporated.

Leininger, MM 1991: Transcultural care principles, human rights, and ethicai considerations. Journal of Transcultural Nursing, 3(1):21. 23.

Lynam, MJ 1992: Towards the goal of providing culturally sensitive care: principles upon which to build nursing curricula. Journal of Advanced Nursing, 17(2):149-157.

Masipa, A 1991: Transcultural nursing in South Africa: Prospects for the 1990's. Journal Of Transcultural Nursing, 3(1):3-4.

Murphy, K \& Macleod Clark, J 1993: Nurses' experiences of caring for ethnic-minority clients. Journal of Advanced Nursing, 18(1):442450.

Perry, F 1988: Far from black and white. Nursing Times, 84(10):4041.

Polit, DF \& Hungler, BP 1991: Nursing research: principles and methods; 4th edition. Pennsylvania: JB Lippincott Company.

Rooda, LA 1993: Knowledge and attifudes of nurses toward culturally different patients: implications for nursing education. Journal of Nursing Education. 32(5):209-213.

Strauss, SA 1993: Regshandboek vir verpleegkundiges en gesondheidspersoneel; 6de uitgawe. Kaapstad: King Edward VII Trust. Suid-Afrikaanse Raad op Verpleging 1985: Minimum vereistes vir die opleiding en gids betreffende die onderrig van studente in die program wat lei tot registrasie as ' $n$ verpleegkundige (algemene, psigiatriese en gemeenskaps-) en vroedvrou. (Gebaseer op Regulasie R425, 1985). Pretoria: SARV.

Tripp-Reimer, T; Brink, PJ \& Saunders, JM 1984: Cultural assessment: content and process. Nursing Outlook, 32(2):78-82. 